\title{
Long-term effects of global change on occupancy and flight period of wild bees in Belgium
}

\author{
François Duchenne ${ }^{1,2}$ (D) | Elisa Thébault ${ }^{1}$ | Denis Michez ${ }^{3}$ | Maxence Gérard ${ }^{3}$ (D) | \\ Céline Devaux $^{4}$ | Pierre Rasmont ${ }^{3}$ | Nicolas J. Vereecken ${ }^{5}$ | Colin Fontaine ${ }^{2}$
}

${ }^{1}$ Institute of Ecology and Environmental Sciences of Paris (Sorbonne Université, CNRS, Université Paris Est Créteil, INRA, IRD), Paris, France

${ }^{2}$ Centre d'Ecologie et des Sciences de la Conservation (CNRS, MNHN, Sorbonne Université), Paris, France

${ }^{3}$ Laboratory of Zoology, Research Institute of Biosciences (University of Mons), Mons, Belgium

${ }^{4}$ Institut des Sciences de l'Evolution de Montpellier, Montpellier (Université de Montpellier, CNRS, IRD, EPHE), Montpellier, France

${ }^{5}$ Agroecology Lab, Université Libre de Bruxelles (ULB), Brussels, Belgium

\section{Correspondence}

François Duchenne, Centre d'Ecologie et des Sciences de la Conservation (CNRS, MNHN, Sorbonne Université), Paris, France.

Email: francois.duchenne@mnhn.fr

\section{Funding information}

Ministère de la Transition Ecologique et Solidaire, Grant/Award Number: SJ 3-17; Belgian Federal Science Policy Office, Grant/ Award Number: BR/132/A1/BELBEES; Fonds pour la Formation à la Recherche dans I'Industrie et dans l'Agriculture; Fonds de la Recherche Scientifique; Research FoundationFlanders, Grant/Award Number: 3094785

\begin{abstract}
Global change affects species by modifying their abundance, spatial distribution, and activity period. The challenge is now to identify the respective drivers of those responses and to understand how those responses combine to affect species assemblages and ecosystem functioning. Here we correlate changes in occupancy and mean flight date of 205 wild bee species in Belgium with temporal changes in temperature trend and interannual variation, agricultural intensification, and urbanization. Over the last 70 years, bee occupancy decreased on average by $33 \%$, most likely because of agricultural intensification, and flight period of bees advanced on average by 4 days, most likely because of interannual temperature changes. Those responses resulted in a synergistic effect because species which increased in occupancy tend to be those that have shifted their phenologies earlier in the season. This leads to an overall advancement and shortening of the pollination season by 9 and 15 days respectively, with lower species richness and abundance compared to historical pollinator assemblages, except at the early start of the season. Our results thus suggest a strong decline in pollination function and services.
\end{abstract}

\section{KEYWORDS}

abundance, agricultural intensification, climate change, community, phenology, pollinator, urbanization

\section{1 | INTRODUCTION}

Global change drivers, such as climate warming, agricultural intensification and urbanization, strongly affect pollinators, decreasing their occupancy and advancing their flight periods (Bartomeus et al., 2011; Potts et al., 2010; Roy \& Sparks, 2000). Because pollinators provide key ecosystem functions (Ollerton et al., 2011) and services (Klein et al., 2007), concerns about a pollination crisis have increased over the previous decades (Potts et al., 2010). Lower pollinator occupancy and diversity can indeed translate into lower pollination performance (Biesmeijer et al., 2006; Potts et al., 2010), while shifts of flight periods can induce a temporal mismatch with their mutualistic partners (Gérard et al., 2020; Memmott et al., 2007). However, despite a sustained research effort on the topic, our understanding of both causes and consequences of the pollination crisis is still limited.

First, a good understanding of the mechanisms responsible for observed differences in species responses to global change is currently missing. Recent studies have shown that global change can drive species thrives or declines, making winner and loser species, respectively. Estimated occupancy trends for British pollinators over the last decades show that while populations of most species declined, populations of a few species increased (Powney et al., 2019). 
Similar heterogeneity holds for phenological changes: while most European pollinators advanced their flight period, some others delayed it or appeared unaffected (Duchenne et al., 2020). While heterogeneity in species response is often overlooked, a better understanding of it, in particular by studying species traits that could explain these distinctive responses, can provide insights on both the drivers and mechanisms impacting species (Biesmeijer et al., 2006).

Second, we still know very little about how different species responses, such as changes in pollinator occupancy and flight period, affect pollinator assemblages when they are combined. A pioneering study suggests that species persistence and phenology are not independent, as pollinators flying later in the summer have higher rates of extinction than do early-flying pollinators (Balfour et al., 2018). We also know that pollinators flying earlier in the season tend to advance more their flight period than do pollinators flying later (Bartomeus et al., 2011; Duchenne et al., 2020). As a consequence, joint changes in occupancy and in flight period could affect the seasonal structure of pollinator assemblages, thereby altering pollination networks (Encinas-Viso et al., 2012; Memmott et al., 2007). The joint study of occupancy and phenological species responses is thus key to gain insights on how pollinator assemblages and related function and services are and will be affected by global change.

Finally, understanding of the respective impacts of several global change drivers on species also remains limited, due to a lack of long time series of protocoled data for many species and difficulties to disentangle the effects of correlated environmental changes. Longterm monitoring schemes only exist for a few groups of insects, such as butterflies (Pollard \& Yates, 1994). For most species, the study of how each global change driver affects pollinator occupancy mainly comes from spatial comparisons among areas with distinct levels of disturbance (Pickett, 1989; Winfree et al., 2009). Spatial comparisons have shown that agricultural intensification decreases pollinator occupancy and richness (Grab et al., 2019; Kremen et al., 2002; Le Féon et al., 2010) but have yielded contrasting results regarding the effect of urbanization on pollinator occupancy or/and richness (Bates et al., 2011; Deguines et al., 2012; Fortel et al., 2014). However, spacefor-time substitution often neglects local adaptation and site history, which can lead to opposite trends in spatial and temporal patterns (Adler \& Levine, 2007; Isaac et al., 2011; White \& Kerr, 2006). This stresses the need to study temporal series to unambiguously identify the drivers of temporal variations (Maria et al., 2013). One potential source of long time series of data come from museum and private collections (Bartomeus et al., 2019). Such data are increasingly used to assess shifts in flight periods (Bartomeus et al., 2011; Hassall et al., 2017) or changes in the occupancy of pollinators (Powney et al., 2019).

The drivers of temporal changes in species responses are difficult to identify because several drivers might exhibit correlated temporal trends but nonetheless can have independent impact on species responses. For example, climate warming, which is generally suspected to be driving the observed shifts in flight period of pollinators, correlates with urbanization that also affects the phenology of pollinator activity (Luder et al., 2018). Similarly, agricultural intensification and climate warming have been shown to affect the persistence of bumblebees (Goulson et al., 2008; Soroye et al., 2020) and they both increased in recent decades. This points out the importance of simultaneously testing several potential drivers if one wants to identify the main threats for pollination.

Here we tackled the three points presented above: (a) identify the species traits related to positive and negative occupancy and flight date shifts; (b) assess how these species responses combine themselves thereby affecting wild bee assemblage; and (c) quantify the independent effects of four global change drivers-that is, agricultural intensification, urbanization, temperature trend, and interannual temperature changes-on the shifts in species occupancies and species flight dates. We based our analysis on the estimation of the temporal trends in occupancy and mean flight date over the last 70 years for 205 bee species in Belgium, using relevant statistical methods to correct bias associated with historical opportunistic data, such as temporal variations in sampling pressure and temporal autocorrelation. By investigating these three points using a unique dataset, we show how several drivers of global change affect biodiversity from individual species to species assemblage and discuss associated risks for the related function and services.

\section{2 | MATERIALS AND METHODS}

\section{1 | Methods overview}

Our goal was threefold: (a) estimate temporal trends in occupancy and flight date of numerous bee species as well as identify traits related to the variation among species; (b) quantify the changes in the seasonal structure of the bee assemblage between 1950 and 2016; and (c) estimate the independent effects of global change drivers on occupancy and mean flight date over the last 70 years. The first step, common to the three goals, consisted in computing unbiased national and annual estimates of occupancies and mean flight dates from historical data (Figure 1). For the first goal, we estimated linear temporal trends of occupancy and mean flight date and we identified species traits associated with those trends, while controlling for species phylogenetic dependence (Figure 1). For the second goal, we combined the annual estimates of occupancy and mean flight date to reconstruct the seasonal structure of the bee assemblage by decades (Figure 1). For the third goal, we correlated yearly changes in occupancies and mean flight dates with yearly changes in the four potential drivers (Figure 1), that is, agricultural intensification, urbanization, temperature trend, and interannual temperature changes. Analyzing yearly changes decreases the expected correlation among potential drivers and their correlation with time (Figure S1), allowing a better insight into the size effects of the potential drivers on the species responses.

\subsection{Dataset and species selection}

Records of bees from Belgium were compiled from the database Banque de Données Fauniques de Gembloux et Mons. This dataset 
FIGURE 1 Statistical steps applied on the bee dataset. Red boxes correspond to statistical models, black text to raw data or intermediate estimates and blue boxes to the goals. MFD, mean flight date

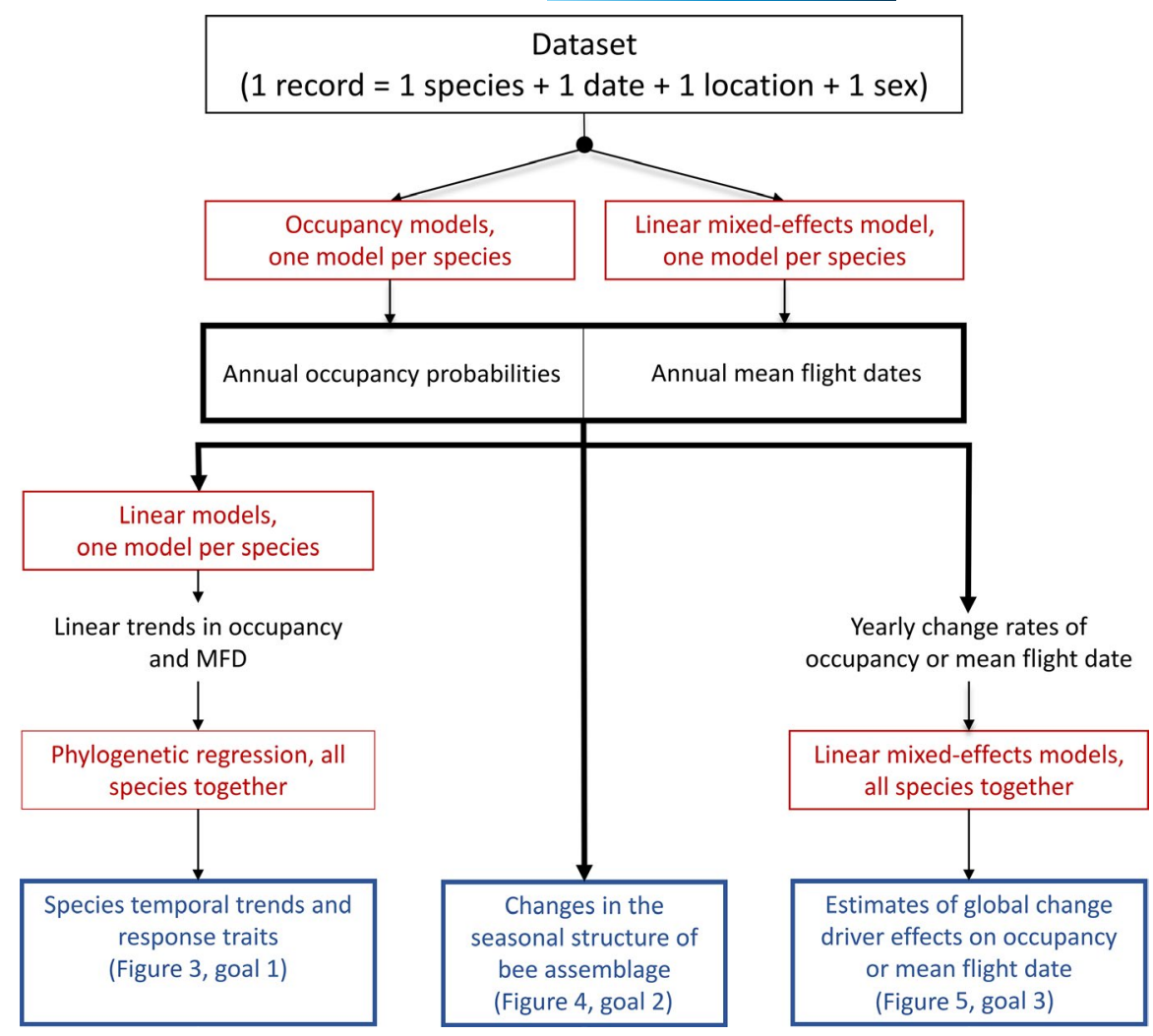

contains about 269,000 records from 1810 to 2017 , for 412 bee species within or at the margins of Belgium (Table S1; Figure S2). Here we used occurrence records, constituted by a species name, a sex, a date of collection, and a location, providing latitude, longitude, and elevation. Because we want to estimate flight period shifts and occupancy trends over a period relevant for the study of the effects of global change and because bee records from the first part of the century are sporadic, we trimmed the dataset to restrict it to records pertaining to the period 1950-2016, and retained wild bee species with at least 30 records for the 1950-2016 period and spread all along the time period studied: with more than one record before 1980, between 1980 and 1990 and after 1990. These filtering steps led to a dataset of 179,948 records belonging to 205 wild bee species (Figure S2).

\section{3 | Annual estimates of occupancy probability and mean flight date}

We estimated a national mean flight date for each year of the time period and each bee species using the occurrence data. We used the predictions from a linear mixed-effects model for each species to get mean flight date estimates that account for variations in space and time of collection location. This model explains variation in the collection dates of a bee species by a polynomial relation with year, to model the temporal trend of mean flight date, and by latitude, longitude and altitude to account for collection location. We also added a random year effect, to account for interannual variation in mean flight dates, and a random sex effect to control for its expected effect. For some records, information about the sex was missing and thus inferred (cf. Method S1).

$$
\begin{aligned}
\text { FD }_{i j s}= & \beta_{0}+\beta_{1} \times \text { years }_{j}+\beta_{2} \times \text { years }_{j}^{2}+\beta_{3} \times \text { years }_{j}^{3}+\beta_{4} \times \text { latitude }_{i} \\
& +\beta_{5} \times \text { longitude }_{i}+\beta_{6} \times \text { altitude }_{i}+\varphi_{j}+\theta_{s}+\varepsilon_{i j s},
\end{aligned}
$$

where $\mathrm{FD}_{i j s}$ is the day of the year of observation $i$ belonging to sex $s$ and year $j, \beta_{0}$ is the intercept, $\beta_{1}, \beta_{2}$, and $\beta_{3}$ are polynomials coefficients of the year effect, $\beta_{4}, \beta_{5}$, and $\beta_{6}$ are the respective coefficients for latitude, longitude, and altitude effects. $\varphi_{j}$ and $\theta_{s}$ are random year and sex effects respectively, and finally $\varepsilon_{i j s}$ is an error term; random terms are all expected to be independent, identically distributed, and homoscedastic.

We used the Bayesian method from Powney et al. (2019) to get estimates of national and annual probabilities of occupancy for each species separately. This method, developed for opportunistic data, accounts for temporal variation in detection probability, thereby taking into account changes over time in the species targeted by collectors. The method also infers non-detection events, as required for opportunistic data. We aggregated records spatially using a grid cell with a cell size of $0.01^{\circ}$ of latitude/longitude and temporally by the day of the year, excluding grid cells with data from a single year. We defined a species detection in a given grid cell and day as the collection of the targeted species at this location and date. Conversely, we defined non-detection for a species in a given grid cell and a given day as the absence of the targeted species while at least another 
wild bee was collected at this location and date. We used the following occupancy model independently for each species:

$$
\begin{gathered}
\text { State model: } z_{i j} \sim \operatorname{Bernoulli}\left(\psi_{i j}\right) \text {; logit }\left(\psi_{i j}\right)=b_{j}+u_{i} \\
\text { Detection model: } y_{i j v} \mid z_{i j} \sim \operatorname{Bernoulli}\left(z_{i j} \times p_{i j v}\right), \\
\operatorname{logit}\left(p_{i j v}\right)=\alpha_{j}+\delta \times \log \left(\mathrm{NS}_{i j v}\right)+\gamma_{3} \times \frac{1}{\beta_{2} \times \sqrt{2 \pi}} e^{-\frac{\left(\mathrm{FD}-\gamma_{1}\right)^{2}}{2 \gamma_{2}^{2}}},
\end{gathered}
$$

where $z_{i j}$ is the true (unknown) status of the species ( 0 absent or 1 present) and $\psi_{i j}$ is the probability of occupancy of grid cell $i$ at year $j$, and which is modeled as a fixed year effect $b_{j}$ and a random grid cell effect $u_{i} . y_{i j v}$ represents the detection status for the same species ( 1 or 0 ) at grid cell $i$, year $j$, and visit $v$ defined by the collection date. $p_{i j v}$ is the estimated probability of detection at grid cell $i$, year $t$ and visit $v$, is conditional upon $z_{i j}=1$ and modeled as a random year effect $\alpha_{j}$, accounting for variation in detectability among years. $\delta$ is the effect of the sampling effort, approximated by the logarithm of the number of species $\left(\mathrm{NS}_{i j \mathrm{j}}\right)$ detected in the cell $i$ on year $j$ and visit $v$. Because we log transformed the number of species collected, this effect captures whether during a visit, one, few, or more species were detected, which mainly depends on the sampling pressure and not so much on the species richness of the site which should be captured by the grid cell effect $u_{i}$ (Isaac et al., 2014). $\gamma_{1}, \gamma_{2}$, and $\gamma_{3}$ are effects of the day of the year of the visit (FD), with a bell-shaped function modeling the flight period.

We fitted the occupancy model for each species separately using the Sparta R package (Isaac et al., 2014), with two chains, 50,000 iterations, a burnin of 35,000 , and a thinning rate of 3 . We used the random walk half-cauchy prior formulation used by Outhwaite et al. (2018), which improves the convergence of the models. For some species, the convergence was not good enough (less than $60 \%$ of occupancy estimates with Rhat $<1.1$ ). For these species, we used 65,000 iterations with a burnin of 50,000 . To estimate the annual proportion of Belgium occupied a given year by a given wild bee species, that is, occupancy, we averaged its predicted presences $\left(z_{i j}\right)$ over all grid cells for the corresponding year. Occupancy measured as such reflects the abundance of a species, due to the close relationship between both (He \& Gaston, 2003).

Finally, the national annual mean flight date estimates correspond to the predictions from Equation (1), for the average longitude, latitude, and altitude of records of the corresponding bee species, while annual occupancy probabilities correspond to the predictions from Equation (2), averaged over all grid cells.

\section{4 | Goal 1: Temporal trends and correlation with species traits}

To asses if we could identify species traits related to the changes in species occupancy and mean flight date, we first estimated linear temporal trends for occupancy and mean flight date, and this for each species independently. To do so, we regressed annual occupancy and mean flight date estimates on years, accounting for the precision of the estimates by weighting them by the inverse of their associated SEs and considering only years with records to estimate mean flight date temporal trend.

Second, we built a database of species traits derived from collection materials, literature, and data analyses based on our database and the European records of Hymenopterans from GBIF. This database is complete for 200 species (Method S2; Table S3). We also built a phylogeny including 203 wild bee species (Method S3). Overall, this led to 199 bee species with complete trait data and included in the phylogeny. We considered species traits that have already been documented as correlated to either changes in occupancy/abundance or mean flight date shifts as follows: mean flight date over years (Bartomeus et al., 2011), flight period length (Bartomeus et al., 2013), species temperature index, measured by the average temperature preference of a species (Bartomeus et al., 2013), species continentality index, measured by the variability of the climatic conditions experienced by a species through its geographic range (Rasmont et al., 2015), intertegular distance as a proxy of bee size (Bartomeus et al., 2013), overwintering location (Williams et al., 2010), sociality (Powney et al., 2019; Williams et al., 2010), and pollen diet generalism, that is, polylectic versus oligolectic (Bartomeus et al., 2013; Williams et al., 2010). Details on these traits can be found in Method S2.

Finally, we explained linear temporal trends in occupancy and mean flight date with species traits, using a phylogenetic generalized least squares model implemented in the caper $\mathrm{R}$ package (Orme et al., 2013), controlling for the Pagel's $\lambda$ at the maximum likelihood, a robust measure of phylogenetic signal (Pagel, 1999). We first checked for collinearity problems in the model by calculating a generalized variance inflation factor, and because we did not get values upper to five, we then used a backward selection of variables based on Akaike Information Criterion (AIC). We removed traits one by one to get the lowest possible AIC value and we stopped to remove species traits from the model when it was not possible to decrease the AIC anymore.

\section{5 | Goal 2: Consequences for the seasonal structure of the wild bee assemblage}

To assess how changes in occupancies and mean flight dates affect the species assemblage, we reconstructed the seasonal structure of the wild bee assemblage, at national scale, for each decade of the studied period. To do so, for each species and decade, we first modeled the flight phenology as a Gaussian curve, with the mean corresponding to the average of annual mean flight date estimates over the decade and SD (i.e., flight period length) corresponding to the $S D$ of the date of flight records (i.e., Method S2). Thus, we assumed that species flight period length was constant over decades, which is verified for $93 \%$ of the species, but are different among species.

Second, to account for variation in occupancy among species and decades, we multiplied each Gaussian, which estimates the phenology of a species at a given decade, by the respective occupancy calculated as the average of annual occupancy probability estimates 
over the decade and species of interest. This gave us the daily occupancies of each species in each decade.

Finally, for each decade, we summed over all species and separately for each day of the season these species daily occupancies, thereby obtaining the daily total occupancy of the pollinator assemblage throughout the season. We then characterized the seasonal structure of wild bee assemblages by its peak date and duration, calculated as the number of days with daily total occupancy of the pollinator assemblage above 0.01 or 0.05 . We also calculated the daily species richness for each decade, as the number of species with a daily occupancy probability above .002 .

To evaluate the respective contribution of changes in occupancy and mean flight date to changes in the phenological structure of the wild bee assemblage, we also reconstructed the daily total occupancy of the pollinator assemblage when only considering changes in occupancy (keeping mean flight date constant, with the species values from 1950) or only considering changes mean flight date (keeping occupancy constant, with the species values from 1950).

\section{6 | Goal 3: Identifying the global change drivers of species responses}

We focused on agricultural intensification, urbanization, and temperature changes as potential drivers of changes in occupancy and mean flight date of bees. Data on these drivers were extracted at the country level (i.e., national average value) for the period 1930-2016. These drivers are all strongly correlated with time, and consequently among them, and cannot be used in the same statistical model. We instead analyzed the relationship between yearly changes in occupancy and mean flight date and yearly changes in global change drivers. Indeed, the yearly changes in the drivers are less correlated with time and among them than raw values (Figure S1), allowing to better untangle the respective effects that each potential driver have on occupancy and mean flight date. Finally, as we expected the drivers to affect differently the bee species, especially those with declined versus increased occupancy over years or those with advanced or delayed mean flight dates over years, we divided the bee species into groups of increasing, decreasing or stable occupancy, and independently into groups of advancing, delaying or stable mean flight date.

\subsection{Data on global change drivers}

For the climatic driver of global change, we used the mean annual temperature over Belgium from the Brussel-Uccle observatory. As temperature exhibits both a trend and strong interannual variability, both of interest, we split these data into two variables: one describing the trend, which corresponds to temperatures smoothed over time, and one describing the interannual temperature changes, and which simply corresponds to raw temperature data. To obtain the temperature trend, we smoothed temperature data using a locally estimated scatterplot smoothing (LOESS), with a span parameter of
0.5 . Note that results shown below are robust across a wide window of smoothing parameter values (Figure S5).

We based our proxy of agricultural intensity on mean wheat yield, as previously done (Donald et al., 2006; Storkey et al., 2012), extracted from the World in Data (https://ourworldindata.org). Annual wheat yield depends on both agricultural practices and climatic conditions. To remove the effect of interannual climatic variability and focus on the long-term trend of wheat yields, which is mainly related to agricultural intensification (Zhai et al., 2017), we smoothed the annual mean wheat yields using LOESS with a span parameter of 0.5 (Figure S4).

We based our proxy of urbanization on the total built-up area in Belgium, which was extracted from the HYDE database V3.2 (Goldewijk et al., 2011). The total built-up area in Belgium was available every 10 years before 2000 and every years after 2000. As total built-up area in Belgium is not expected to show any interannual variations around the trend, we interpolated missing data using a LOESS with a span parameter of 0.2 (Figure 2).

\subsection{From time series to yearly changes}

Once the time series were obtained for the four components of global change, we computed their yearly changes $\Delta D_{j}$ by taking the difference between year $j$ and $j-1$ for each variable $D$, and scaled that difference with the $S D$ of the $\Delta D$ time series. Standardizing $\Delta D_{j}$ allows providing the same potential effect of each driver of global change on the response variables. Those yearly changes in the global change variables correspond to the global change drivers.

In a similar way, we computed the yearly change for species $k$ from year $j-1$ to year $j$ in occupancy or mean flight date, $\Delta_{\mathrm{O}_{j k}}$ and $\Delta_{\mathrm{MFD}_{j k}}$, from the logit of the annual occupancy probabilities (O) and mean flight dates. To account for estimation errors, for each variable $X$, occupancy or mean flight date, we combined the SEs of the 2 years used to calculate that of the yearly changes as follows: $S E_{\Delta X_{j}}=\sqrt{S E_{j-1}^{2}+S E_{j}^{2}}$. To compute those yearly changes, we used only occupancy rates that converged well (Rhat $<1.1$ ) and mean flight date predicts corresponding to years with records of the given species. Moreover, since some occupancy yearly changes exhibit a very high associated $S E$, we removed all $\Delta_{O_{j k}}$ with a $S E \geq 30(n=409$ on 9,541 ) to avoid including very uncertain data in the following analysis. In the same way, we removed the few mean flight shifts with an absolute value $\geq 50$ days ( $n=41$ on 6,842 ), because it is very unlikely they occurred between two consecutive years and more likely were produced by mistakes in collection dates.

\subsection{Testing for the effects of global change drivers}

We expected distinct effects of global change drivers on species depending on their responses. For example, we expect agricultural intensification to affect differently bees that exhibit a decrease in occupancy from those exhibiting an increase. We thus classified bee species in three groups according to their temporal linear trends in occupancy: significantly 
(a)

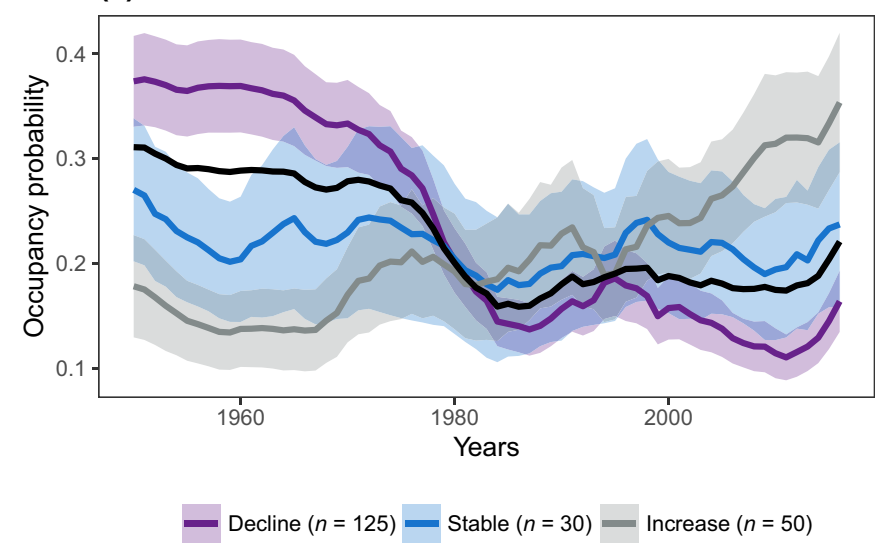

(b)

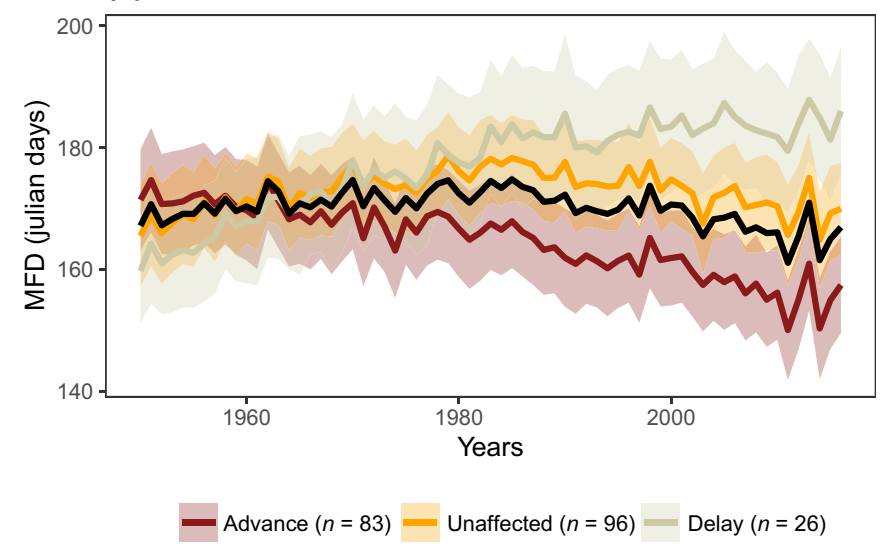

(c)

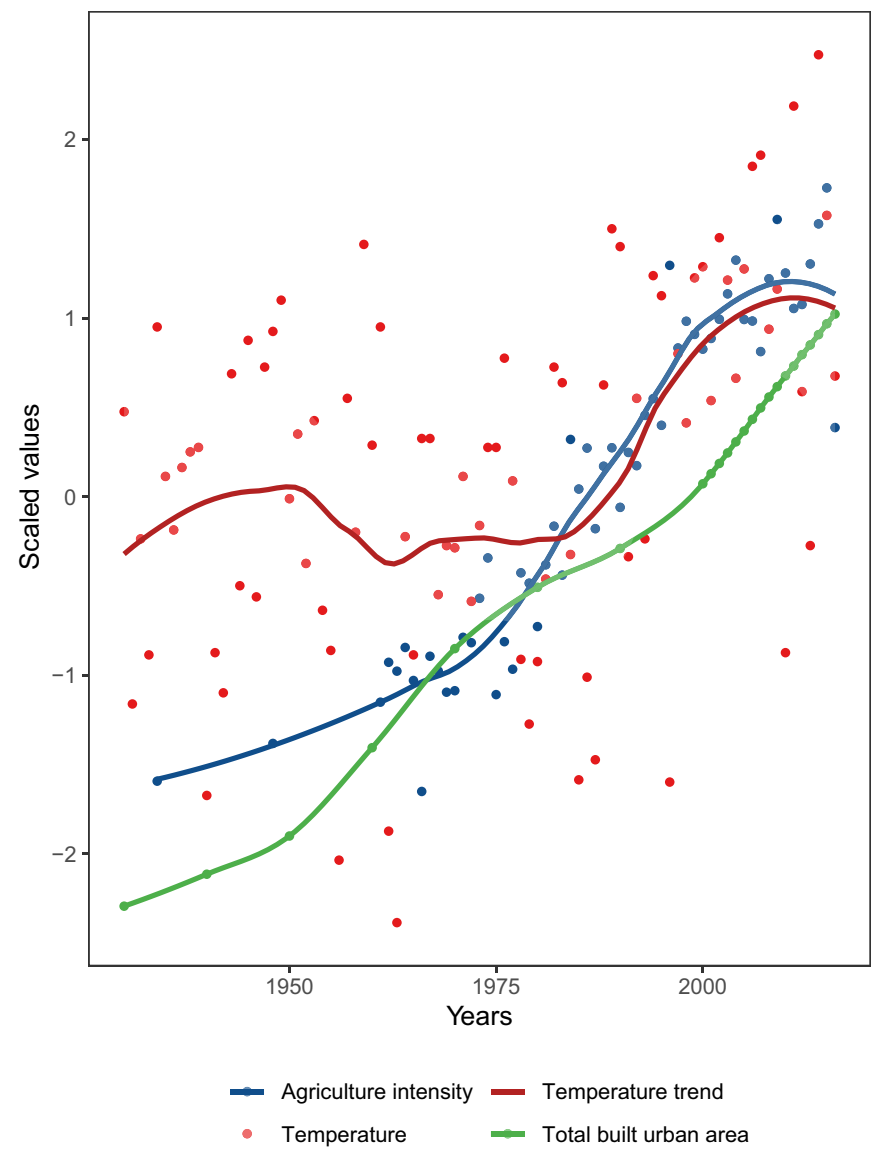

FIGURE 2 Occupancy and mean flight dates changes over time and trends in global change variables. Predicted variation of (a) occupancy probability and (b) mean flight date across years averaged by species groups, and their associated $\mathrm{Cl}_{95 \%}$ interval represented by ribbons. Black lines represent the average value over all species. (c) Scaled (centered by mean and scaled by SD) values of the global change variables (circles) and values used to calculate drivers (lines)

increasing species (winners), significantly declining species (losers), and stable species for those with non-significant temporal trend. Similarly for the mean flight date, we split species into three groups according to their temporal linear trends: advancing, delaying, and unaffected species.

We tested for the effect of scaled yearly changes in the four drivers of global change $\left(\Delta D_{j}\right)$, that is, agricultural intensification (A), urbanization $(U)$, temperature trend, and interannual temperature changes, on yearly changes in occupancy $\Delta_{O}$ and mean flight date $\Delta_{\text {MFD }}$. We built two independent linear mixed models accounting for species groups and their interaction with the drivers. We added a random species effect to take into account that all species do not have the same number of $\Delta_{O}$ or $\Delta_{\mathrm{MFD}}$, and a Ornstein-Uhlenbeck covariance structure to take into account temporal autocorrelation. We included only wild bee species for which at least 25 yearly changes could be calculated ( $n=168$ for occupancy, $n=128$ for mean flight date):

$$
\begin{aligned}
\Delta_{X_{k g j}}= & \beta_{\mathrm{O}_{g}}+\beta_{\mathrm{A}_{g}} \times \Delta \mathrm{A}_{\mathrm{j}}+\beta_{\mathrm{ITC}_{g}} \times \Delta \mathrm{ITC}_{j}+\beta_{\mathrm{TT}_{g}} \times \Delta \mathrm{TT}_{j} \\
& +\beta_{\mathrm{U}_{g}} \times \Delta \mathrm{U}_{j}+\varphi_{j_{(k)}}+\varepsilon_{k g j}
\end{aligned}
$$

where $\Delta_{X_{k g j}}$ are the yearly changes in variable $X(\mathrm{O}$ or mean flight date) of the species $k$ belonging to the group $g$, on the year $j$. $\beta_{O_{g}}$ is the intercept, $\beta_{\mathrm{A}_{g}}, \beta_{\mathrm{TT}_{g}}, \beta_{\mathrm{ITC}}$ and $\beta_{\mathrm{U}_{g}}$ are standardized effects of the drivers, depending on the group $g$ of the species. $\varphi_{j_{(k)}}$ is a year random effect depending on the species $k$ used to implement the Ornstein-Uhlenbeck covariance structure. $\varepsilon_{k g j}$ is the error term, expected to be independent, identically distributed and homoscedastic. We implemented the model using the R package gImmTMB (Brooks et al., 2017). To account for statistical uncertainties, yearly changes were weighted in the model by the inversion of their SEs. For occupancy, these weights were elevated at power 0.2 , to avoid very heterogeneous weights leading to convergence problems. We also checked for collinearity among variables by calculating a variance inflation factor values for global change drivers. We did not get values above five, suggesting that collinearity among driver should bias estimates.

\section{3 | RESULTS}

\section{1 | Species responses}

Across all bee species over 1950-2016 in Belgium, occupancy and mean flight date yearly estimates reveal that the occupancy 
(a)

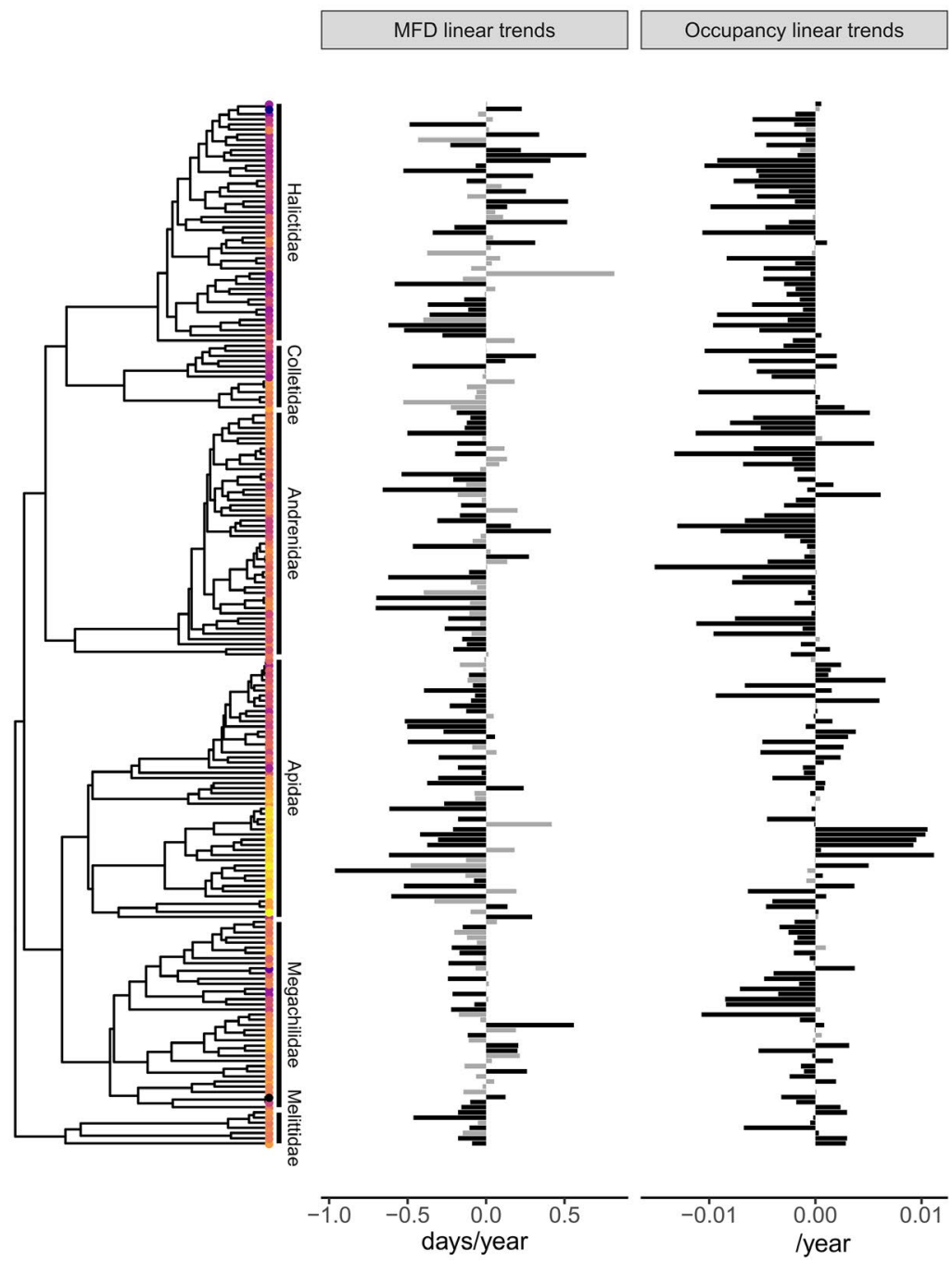

(b)

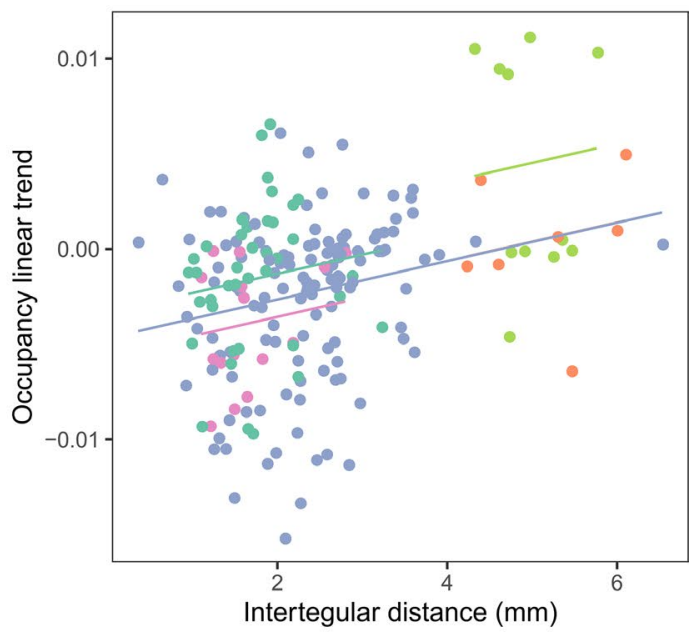

(c)

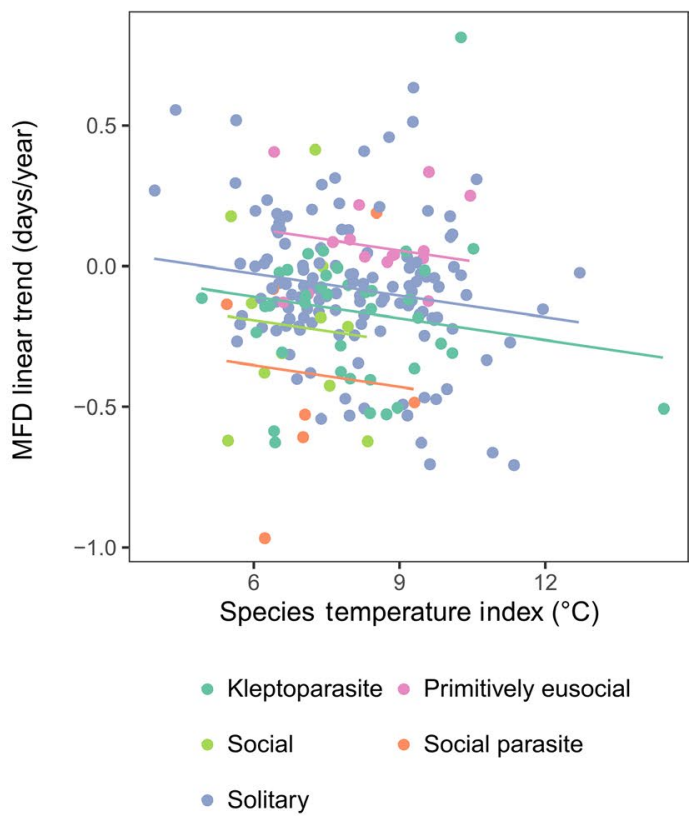

FIGURE 3 Traits related to the linear temporal trends in occupancy and mean flight date over the study period. (a) Relationships among phylogeny, bee size measured as intertegular distance (ITD) and temporal linear trends in occupancy and mean flight date, for the species included in the phylogeny $(n=203)$. ITDs are represented by the leaf color of the phylogeny. Black leaf represent the species with no value of ITD $(n=1)$. Black bars represent significant trends while grey bars represent non-significant trends. (b) Relationships among ITD, sociality behavior and occupancy trends $(n=199)$. (c) Relationships among species temperature index, sociality behavior and mean flight date linear trends $(n=199)$. Lines represent the prediction of the phylogenetic generalized least squares regressions. Values of mean flight date shifts and occupancy trends are shown in Table S4

decreased on average by about 33\% (Figure 2a) and that bees were active earlier, on average, by about 4 days (Figure $2 b$ ). Linear trends in occupancy per species indicate that distributions have shrunk for 125 "loser" species (61\%) whereas 30 "stable" species (14\%) did not exhibit any significant change, and 50 "winner" species (24\%) had increased their distribution areas (Figure 3a; Table S4). Turning to flight period, we find a significant linear advancement of the mean flight date for 83 species (40\%), 96 species (47\%) were unaffected, and 26 species (13\%) delayed their mean flight dates (Figure 3a; Table S4). Note that over the 1950-2016 period, global change accelerated, as shown by the trends in the four potential drivers tested here (Figure 2c).

\subsection{Correlation between species responses and species traits}

We find that several species traits correlated to species responses. The social behavior of bees is associated with both the occupancy and mean flight date linear trends over years, with social bee populations declining less and advancing more their flight date than the primitively eusocial and solitary ones (Figure 3; Table 1). The thermal niche of species is also related to the linear trends in mean flight date, with southern species advancing their flight period more than do northern ones (Figure 3c). Finally, we find that bee size is strongly 
TAB LE 1 Estimates, SEs, and $p$-values for both phylogenetic generalized least squares models (PGLS) explaining linear trends in occupancy and mean flight date (MFD, $n=199$ ). NA (non-attributed) values indicate that the selection based on the AIC removed this trait for this response. Pagel's $\lambda$ values included in the PGLS (taking into account species trait effects) and rough Pagel's $\lambda$ values (without taking into account species trait effects) are indicated. Pagel's $\lambda$ equal to 0 means that there is no phylogenetic signal, while a value significantly different from 0 means that there is a phylogenetic signal

\begin{tabular}{|c|c|c|c|c|c|c|c|}
\hline & & \multicolumn{3}{|c|}{ Mean flight date linear temporal trends } & \multicolumn{3}{|c|}{ Occupancy linear temporal trends } \\
\hline \multicolumn{2}{|c|}{ Species Temperature Index } & -0.02579 & 0.01154 & .02657 & 0.00035 & 0.00019 & .06671 \\
\hline \multirow{3}{*}{$\begin{array}{l}\text { Sociality } \\
\text { (ref = Kleptoparasite) }\end{array}$} & & - & - & .0001 & - & - & .0257 \\
\hline & Social parasite & -0.24401 & 0.10322 & - & -0.00134 & 0.00219 & - \\
\hline & Social & -0.08412 & 0.08660 & - & 0.00280 & 0.00195 & - \\
\hline \multicolumn{2}{|l|}{ Mean flight date } & 0.00010 & 0.00106 & .04933 & NA & NA & NA \\
\hline \multicolumn{2}{|l|}{ ITD } & NA & NA & NA & 0.00101 & 0.00040 & .01222 \\
\hline \multicolumn{2}{|l|}{ Pagel's $\lambda$ (PGLS) } & \multicolumn{3}{|c|}{$0.00 ; \mathrm{Cl}_{95 \%}[0.00,0.08]$} & \multicolumn{3}{|c|}{$0.02 ; \mathrm{Cl}_{95 \%}[0.00,0.18]$} \\
\hline
\end{tabular}

(a)

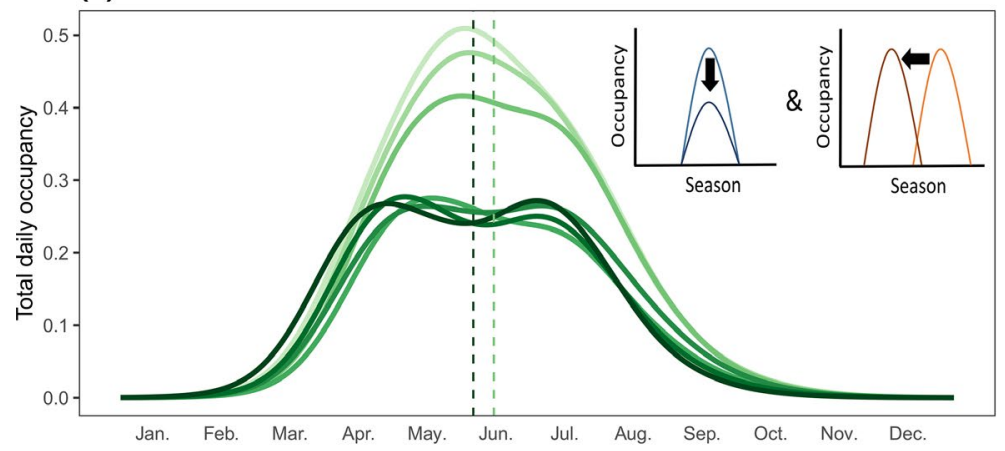

(b)

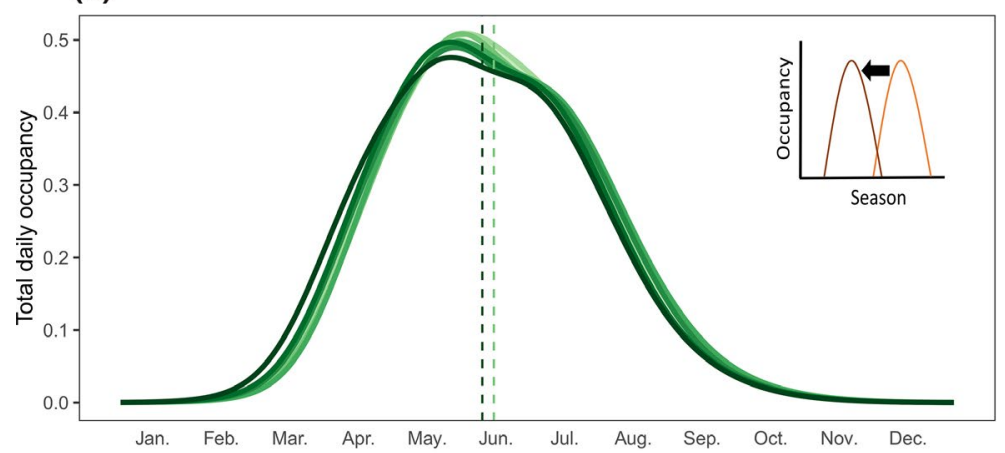

(c)

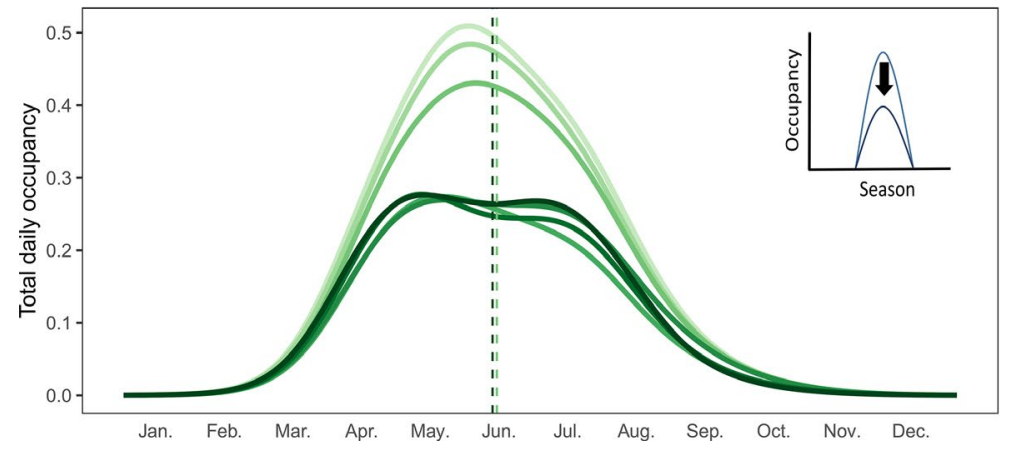

Years

- 1950-1959

- 1960-1969

- 1970-1979

- 1980-1989

- 1990-1999

- 2000-2009

- 2010-2016

Years

- 1950-1959

- 1960-1969

- 1970-1979

- 1980-1989

- 1990-1999

- 2000-2009

- 2010-2016

Years

- 1950-1959

- 1960-1969

- 1970-1979

- 1980-1989

- 1990-1999

- 2000-2009

- 2010-2016
FIGURE 4 Seasonal variations of the total occupancy of pollinators over decades. (a) Reconstruction considering both occupancy and mean flight date changes, (b) reconstruction considering only mean flight date shifts, historical occupancy being fixed over decades, and (c) reconstruction considering only occupancy changes, historical mean flight date being fixed over decades. Dashed vertical lines represent the weighted mean of the seasonal total occupancy distribution for 1950-1959 (light green) and for 2010-2016 (dark green) 
correlated to the occupancy linear trends, with larger species decreasing less their mean occupancy than smaller ones (Figure $3 b$; Table 1), this effect remaining significant when excluding bumblebees, which are especially large species.

We find a significant phylogenetic signal in the occupancy linear trends over time (Table 1), indicating that global change affects some clades of bees more strongly, thereby increasing the loss of phylogenetic diversity. On average, Halictidae $\left(-0.0036 \pm 0.0005\right.$ year $\left.^{-1}\right)$ and Andrenidae $\left(-0.0034 \pm 0.0007\right.$ year $\left.^{-1}\right)$ are the most declining families while Melittidae (0.0002 \pm 0.001 year $\left.^{-1}\right)$ and Apidae $\left(0.0008 \pm 0.0006\right.$ year $\left.^{-1}\right)$ slightly gained in occupancy over time. Such phylogenetic signal is likely due to strong links between occupancy trends and phylogenetically conserved traits, like bee size (Figure 3a), as this phylogenetic signal disappears when accounting for the effect of response traits (Table 1). We do not find any significant phylogenetic signal in mean flight date linear trends (Table 1).

\subsection{Consequences of occupancy trends and mean flight date shifts on the bee assemblage}

The temporal linear trends in mean flight date and occupancy were negatively correlated $(r=-.14, p=.04$; Figure $S 6)$ : species that show an increase in occupancy probabilities over time tend to advance their mean flight date, while those that show a decrease in occupancy tend to delay their mean flight date. By reconstructing the seasonal structure of bee assemblages throughout the study period using yearly estimates of occupancy and mean flight date, we show that this correlation between the two species responses resulted in a synergistic effect on the seasonal structure. The peak of total daily occupancy is 8.97 days earlier in the recent decade compared to 1950-1960 when both occupancy and mean flight date changes are considered (Figure 4a), while it is 5.05 days earlier when only mean flight date changes are taken into account (Figure 4b), and 1.87 days earlier when only occupancy changes are considered (Figure 4c). The predicted additive effect of

(a)
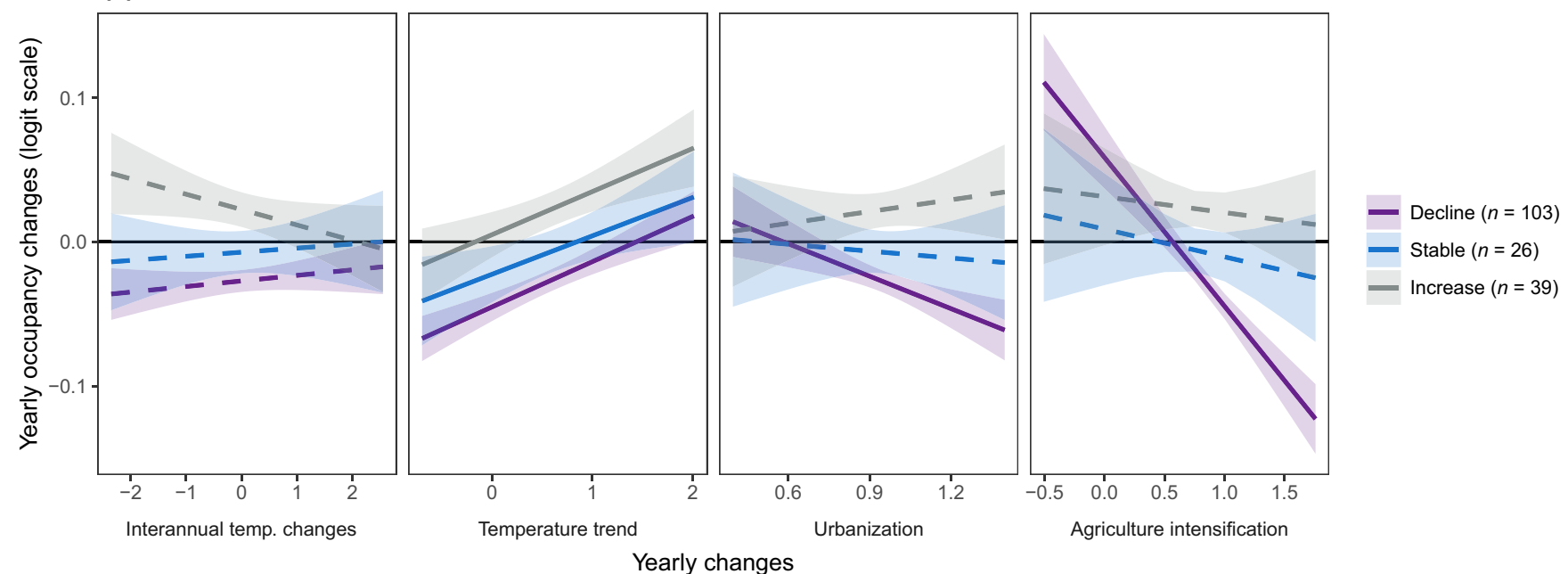

(b)
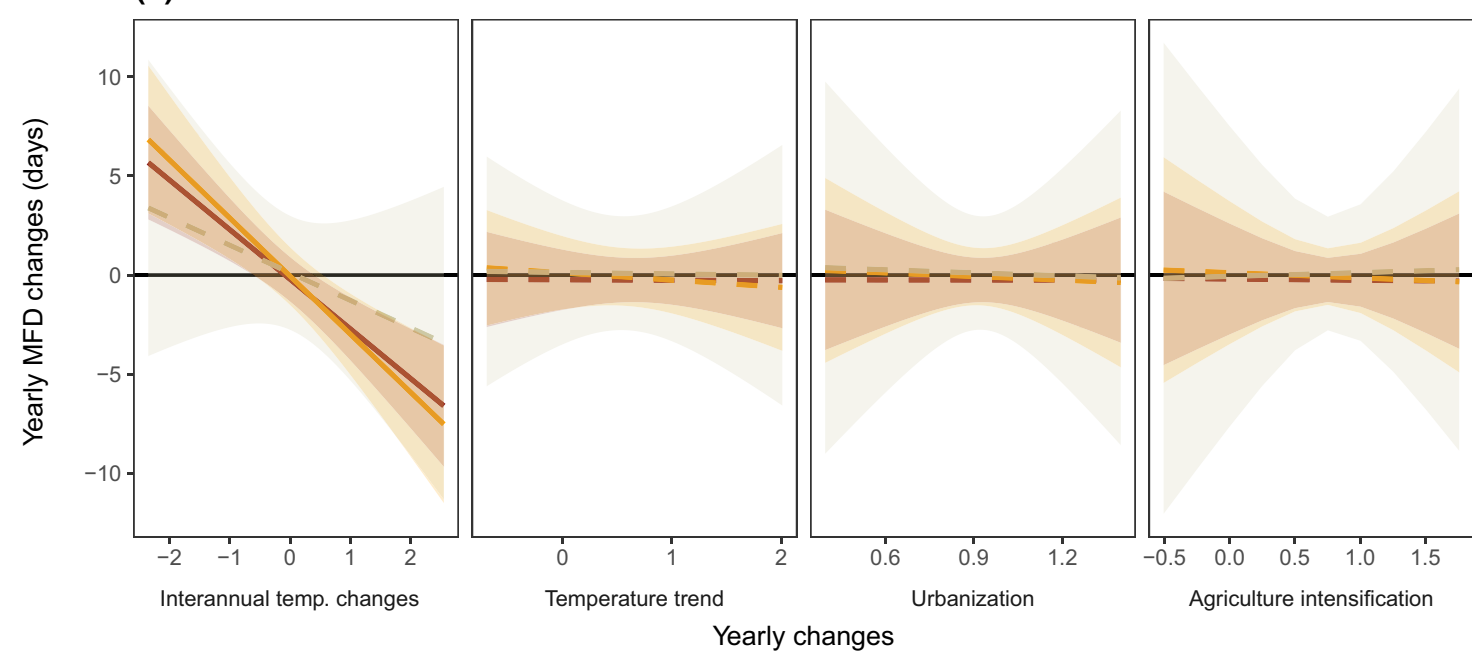

- Advance $(n=64)$

- Unaffected $(n=50)$

- Delay $(n=14)$

FIGURE 5 Drivers of occupancy and mean flight date yearly changes depending on species group regarding their temporal linear trends for occupancy and mean flight date. (a) Occupancy yearly changes and (b) mean flight date yearly changes against yearly changes of global change variables, previously scaled (divided by SD). The lines show the mixed-effect model predictions with their SEs (ribbon). Dashed lines represent slopes that are non-significantly different from 0 and solid lines represent slopes significantly different from 0 
changes in mean flight dates and occupancy thus corresponds to a peak earlier by 6.92 days, which remains below the predicted change when both species responses are studied jointly. Overall, the average season date has advanced by about 9 days between 1950 and 2016 (Figure S6), while season length has shortened by about 15 days (Figure S7a). We also observe a shift from a unimodal distribution in 1950 to a bimodal distribution of bee total occupancy and species richness in 2016 (Figure 4a; Figure S7b). All along the season excepting at its early beginning, the total occupancy and the richness of wild bee in the present time is lower than in 1950.

\subsection{Drivers of bee decline and flight period shifts}

To investigate the potential drivers of each species response, we correlated the yearly changes of occupancy and mean flight date to the scaled yearly changes of drivers of global change, allowing for differences among groups of species. Winner, stable, and loser bee species all benefited from temperature increase, their occupancy being positively and consistently correlated to temperature trend (Figure 5a). Agricultural intensification and urbanization correlated negatively with the occupancy yearly changes of declining bees but not with the ones of stable or increasing species (Figure 5a; Table S5). Note that the effect size (estimates) of urbanization on loser species is smaller than that of agricultural intensification; changing the smoothing parameter for the urbanization affects the estimates of urbanization (Figure S5). As a consequence, agricultural intensification was most likely the main driver of the decline of wild bee species in Belgium over the last 70 years. Interannual temperature changes did not significantly correlate with occupancy yearly changes (Figure 5a; Table S6), indicating that it is not a main driver of wild bee occupancy in Belgium.

Surprisingly, changes in mean flight date were solely explained by interannual temperature changes, bees being active earlier in warmer years, although not significantly for bees that delay their mean flight date (Figure 5b; Table S7). Temperature trend, urbanization, and agricultural intensification did not show correlation with mean flight date shifts (Figure $5 b$ ).

\section{4 | DISCUSSION}

\subsection{Changes in wild bee assemblage over time}

Our analyses indicate that $61 \%$ of the wild bee species declined and $40 \%$ advanced their mean flight date over the last 70 years. These patterns are consistent with the few studies using time series to describe European bee population trends (Ollerton et al., 2014; Powney et al., 2019), and mean flight date shifts (Bartomeus et al., 2011; Duchenne et al., 2020). The negative correlation between the linear trends over years of occupancy and mean flight date is also consistent with previous results (Balfour et al., 2018), and suggests that these two types of responses jointly contribute to the shift toward early dates of the bee assemblage on average. Our analysis cannot disentangle whether this negative correlation results from a causal relationship or from the fact that both species responses are linked to bee social behavior. A causal link from phenological shifts to species persistence via trophic mismatch is sometimes suggested (Hegland et al., 2009). Such causal relationship is not supported by our data as the bee decline occurred mainly before the shifts in flight periods. However, bee decline could also prevent shifts in flight period, since a strong decline in the population size can decrease the ability to respond to an environmental change because of expected decreased adaptive potential (Willi et al., 2006).

Such correlation between changes in occupancy and mean flight date led to synergistic effects on the seasonal structure of the pollinator assemblage, with the peak of total occupancy happening earlier than expected from additive effects of each response. This exemplifies how studying multiple species responses can benefit our understanding of the consequences of global change. Coupled with the overall decrease in occupancy along the season, such modifications of the seasonal structure of bee assemblage should lead to a decline in pollination function and services, especially for late flowering plants and crops. Studies on plant communities suggest that global change also affects the seasonal structure of flowering (CaraDonna et al., 2014; Diez et al., 2012), which can lead in some cases to a shift from unimodal to bimodal distributions of flowering abundance over the season (Aldridge et al., 2011), mirroring the pattern we find. However, these studies have been so far restricted to local American plant communities and thus cannot be directly compared to our results at national scale, stressing the need to investigate the interplay between the changes in seasonal structure of plants and pollinator communities.

\subsection{Drivers of bee occupancy changes}

Our study shows that the decline of bee populations was likely driven by land-use change, mainly agricultural intensification, and most likely not by climate change. This result is consistent with the negative effect of agricultural intensification found in studies based on spatial comparisons (Grab et al., 2019; Kremen et al., 2002). Agricultural intensification includes many variables that could have a negative effect on bee occupancy. The fact that bigger bees decline less than did smaller ones, could support the main role of two variables already documented having a negative effect on bees: pesticides (Goulson et al., 2015; Park et al., 2015) and habitat destruction (Park et al., 2015). Bigger bees have a higher physiological resistance to pesticides (Rafael ValdovinosNúñez et al., 2009; Uhl et al., 2016) and higher dispersal abilities and foraging distance (Greenleaf et al., 2007), allowing them to suffer less from agricultural intensification than smaller bees. Another interpretation of social and big bees suffering less from agricultural intensification could be that they are especially targeted by conservation plans in agricultural landscapes in Europe (Nieto et al., 2014). However, our results regarding the positive relationships between body size and occupancy trend strongly contrast with previous results, which found that larger bees are more prone to decline than smaller ones (Larsen et al., 2005; Rader et al., 2014; Scheper et al., 2014). These differences 
could emerge because we accounted for changes in detection probabilities over time while previous temporal studies did not (Scheper et al., 2014), which can bias occupancy trends (Isaac et al., 2014).

We also find that urbanization significantly discriminates between losers and winners of global change, suggesting that loser species suffer from urbanization while winners do not. This is consistent with the fact that those winners, social and big bees, are present more in the urban area than solitary bees (Baldock et al., 2015). However, as we use national average time series, neglecting spatial heterogeneity of global change drivers and responses, we are not able to test that the occupancy increase of winners occurs mainly in urban areas. This stresses the need to use spatio-temporal partitioning of the respective role of global change drivers in species responses, but that requires finding massive historical time series of data, which are almost nonexistent for pollinators.

Our analysis further reveals that climate warming had a positive impact on bee occupancy in Belgium, even for declining bees. Such positive impact can be mediated by direct effects on wild bee physiology, as in temperate areas ectotherms are living in a climate cooler than their physiological optima in average (Deutsch et al., 2008), but also by indirect effects through changes in resource availability (Ogilvie et al., 2017). However, climate change could ultimately have an overall negative effect on bees as it involves other aspects than climate warming, such as extreme events, which have been shown to drive bumblebee decline (Soroye et al., 2020).

\section{3 | Drivers of mean flight date shifts}

We do not detect any effect of the tested global change drivers on mean flight date other than the effect of interannual temperature changes. Large interannual temperature increases induce large changes for earlier mean flight date and vice-versa. This suggests that such response could be due to the high phenotypic plasticity of insect flight period (Sgrò et al., 2016), which allows fast responses to interannual temperature changes. However, we do not find any driver explaining the delay of the mean flight date that occurred for some species. This delay might be related to a more specific temperature index, for example, an increase in winter temperature can delay bee emergence (Fründ et al., 2013). Also, we did not account for time-lagged responses in our analyses, while some responses to changes in drivers could occur years after and for a long time. For instance, changing competition pressures along the season because of abundance changes could drive changes in mean flight dates (Rudolf, 2019), including delays for some species. Assessing simultaneously effects with and without time lags would require further methodological developments, but it is a key future step to understand well the effects of global change on biodiversity.

\subsection{Methodological limits and perspectives}

The effects of global change drivers tested here explain only a small part of the variance of changes in occupancy and mean flight date,
$3 \%$ and $5.5 \%$, respectively. This is likely due to several limits of our analysis. First, we looked for effects at the group level, thereby neglecting heterogeneity of response among species within groups. Second, we neglected the spatial heterogeneity in the global change drivers and species responses by analyzing changes at national level. This most probably lowers the part of variance explained but it allows highlighting general patterns over time. Third, as previously mentioned, we neglected time lags in the effects of global change drivers. Instead, we focused on breaking inevitable temporal correlations among global change drivers and time, and decided to limit our study to instantaneous effects only. For example, if agriculture intensification stops, our approach assumes that it has no more effect on bees, species response to perturbation can take years to occur, such as extinction and decline (Kuussaari et al., 2009), and bees could still decline because of high past level of agriculture intensity. Therefore, part of the unexplained variance in the response variable is most probably due to time-lag effects neglected here.

Despite such limits, our study reports an unprecedented quantitative estimation of the contributions of four global change drivers on the average decline and flight period shifts of pollinators over time. We show that the land-use changes were most likely the main drivers of pollinator decline over the last 70 years in Belgium. Such results can probably be generalized to a large part of Western Europe, where global change drivers are following the same trend as in Belgium.

\section{ACKNOWLEDGEMENTS}

We thank Elsa Teulière, Emmanuelle Porcher and Nicolas Loeuille for their insightful comments on the manuscript. We also thank Maxime Drossart for providing the overall bee dataset. This project was funded by the Ministère de la Transition Ecologique et Solidaire as part of the project "What is the sensitivity of pollinators to global warming in France" (convention no. SJ 3-17) lead by Christophe Daugeron and Colin Fontaine, and by the Institut de la Transition Ecologique, Sorbonne Université, as part of the project Yapludsaison (S20JR31002-4). We thank all the people who collected data and we are very grateful for collection access to the curators of the following museums: Wouter Dekoninck and Yvonnick Gérard, IRSNB (Bruxelles, Belgium), Frédéric Francis, GxABT (Gembloux, Belgium). Finally, we also thank the GBIF database and its data providers. This work was partly supported by the "Fonds de la Recherche Scientifique - FNRS," the Research Foundation-Flanders (FWO) under EOS Project named CLIPS (no. 3094785), and the Belgian Science Policy (project BR/132/A1/BELBEES). M.G. was supported by a grant from the Belgian Fonds pour la Recherche dans I'Industrie et l'Agriculture (FRIA). Thanks to the Noun Project (Vectors Point) for making available pictograms used in the graphical abstract.

\section{AUTHOR CONTRIBUTION}

F.D., E.T., C.D. and C.F. designed the study. F.D. performed the statistical analyses. P.R., N.J.V. and D.M. provided distribution records. M.G., N.J.V. and D.M. provided species traits. F.D. wrote the paper with contributions from all authors. 


\section{DATA AVAILABILITY STATEMENT}

The data and codes that support the findings of this study are openly available at https://github.com/f-duchenne/Wild-bees-in-Belgium

\section{ORCID}

François Duchenne (iD https://orcid.org/0000-0002-6917-8013

Maxence Gérard (iD https://orcid.org/0000-0002-2485-0662

\section{REFERENCES}

Adler, P. B., \& Levine, J. M. (2007). Contrasting relationships between precipitation and species richness in space and time. Oikos, 116(2), 221-232. https://doi.org/10.1111/j.0030-1299.2007.15327.x

Aldridge, G., Inouye, D. W., Forrest, J. R. K., Barr, W. A., \& MillerRushing, A. J. (2011). Emergence of a mid-season period of low floral resources in a montane meadow ecosystem associated with climate change. Journal of Ecology, 99(4), 905-913. https://doi.org/ 10.1111/j.1365-2745.2011.01826.x

Baldock, K. C. R., Goddard, M. A., Hicks, D. M., Kunin, W. E., Mitschunas, N., Osgathorpe, L. M., Potts, S. G., Robertson, K. M., Scott, A. V., Stone, G. N., Vaughan, I. P., \& Memmott, J. (2015). Where is the UK's pollinator biodiversity? The importance of urban areas for flower-visiting insects. Proceedings of the Royal Society B: Biological Sciences, 282(1803), 20142849. https://doi.org/10.1098/rspb.2014.2849

Balfour, N. J., Ollerton, J., Castellanos, M. C., \& Ratnieks, F. L. W. (2018). British phenological records indicate high diversity and extinction rates among late-summer-flying pollinators. Biological Conservation, 222, 278-283. https://doi.org/10.1016/j.biocon.2018.04.028

Bartomeus, I., Ascher, J. S., Gibbs, J., Danforth, B. N., Wagner, D. L., Hedtke, S. M., \& Winfree, R. (2013). Historical changes in northeastern US bee pollinators related to shared ecological traits. Proceedings of the National Academy of Sciences of the United States of America, 110(12), 4656-4660. https://doi.org/10.1073/pnas.1218503110

Bartomeus, I., Ascher, J. S., Wagner, D., Danforth, B. N., Colla, S., Kornbluth, S., \& Winfree, R. (2011). Climate-associated phenological advances in bee pollinators and bee-pollinated plants. Proceedings of the National Academy of Sciences of the United States of America, 108(51), 20645-20649. https://doi.org/10.1073/pnas.1115559108

Bartomeus, I., Stavert, J. R., Ward, D., \& Aguado, O. (2019). Historical collections as a tool for assessing the global pollination crisis Philosophical Transactions of the Royal Society B: Biological Sciences, 374(1763), 20170389. https://doi.org/10.1098/rstb.2017.0389

Bates, A. J., Sadler, J. P., Fairbrass, A. J., Falk, S. J., Hale, J. D., \& Matthews, T. J. (2011). Changing bee and hoverfly pollinator assemblages along an urban-rural gradient. PLoS One, 6(8), e23459. https://doi. org/10.1371/journal.pone.0023459

Biesmeijer, J. C., Roberts, S. P. M., Reemer, M., Ohlemüller, R., Edwards, M., Peeters, T., Schaffers, A. P., Potts, S. G., Kleukers, R., Thomas, C. D., Settele, J., \& Kunin, W. E. (2006). Parallel declines in pollinators and insect-pollinated plants in Britain and the Netherlands. Science, 313(5785), 351-354. https://doi.org/10.1126/science.1127863

Brooks, M. E., Kristensen, K., van Benthem, K. J., Magnusson, A., Berg, C. W., Nielsen, A., Skaug, H. J., Maechler, M., \& Bolker, B. M. (2017). GImmTMB balances speed and flexibility among packages for zeroinflated generalized linear mixed modeling. The R Journal, 9(2), 378400. https://doi.org/10.32614/RJ-2017-066

CaraDonna, P. J., Iler, A. M., \& Inouye, D. W. (2014). Shifts in flowering phenology reshape a subalpine plant community. Proceedings of the National Academy of Sciences of the United States of America, 111(13), 4916-4921. https://doi.org/10.1073/pnas.1323073111

Deguines, N., Julliard, R., de Flores, M., \& Fontaine, C. (2012). The whereabouts of flower visitors: Contrasting land-use preferences revealed by a country-wide survey based on citizen science. PLoS One, 7(9), e45822. https://doi.org/10.1371/journal.pone.0045822
Deutsch, C. A., Tewksbury, J. J., Huey, R. B., Sheldon, K. S., Ghalambor, C. K., Haak, D. C., \& Martin, P. R. (2008). Impacts of climate warming on terrestrial ectotherms across latitude. Proceedings of the National Academy of Sciences of the United States of America, 105(18), 66686672. https://doi.org/10.1073/pnas.0709472105

Diez, J. M., Ibáñez, I., Miller-Rushing, A. J., Mazer, S. J., Crimmins, T. M. Crimmins, M. A., Bertelsen, C. D., \& Inouye, D. W. (2012). Forecasting phenology: From species variability to community patterns. Ecology Letters, 15(6), 545-553. https://doi.org/10.1111/j.1461-0248.2012. 01765.x

Donald, P. F., Sanderson, F. J., Burfield, I. J., \& van Bommel, F. P. J. (2006). Further evidence of continent-wide impacts of agricultural intensification on European farmland birds, 1990-2000. Agriculture, Ecosystems \& Environment, 116(3), 189-196. https://doi.org/10.1016/ j.agee.2006.02.007

Duchenne, F., Thébault, E., Michez, D., Elias, M., Drake, M., Persson, M., Piot, J. S., Pollet, M., Vanormelingen, P., \& Fontaine, C. (2020). Phenological shifts alter the seasonal structure of pollinator assemblages in Europe. Nature Ecology \& Evolution, 4(1), 115-121. https:// doi.org/10.1038/s41559-019-1062-4

Encinas-Viso, F., Revilla, T. A., \& Etienne, R. S. (2012). Phenology drives mutualistic network structure and diversity: Effects on the dynamics of mutualistic networks. Ecology Letters, 15(3), 198-208. https://doi. org/10.1111/j.1461-0248.2011.01726.x

Fortel, L., Henry, M., Guilbaud, L., Guirao, A. L., Kuhlmann, M., Mouret, H., Rollin, O., \& Vaissière, B. E. (2014). Decreasing abundance, increasing diversity and changing structure of the wild bee community (Hymenoptera: Anthophila) along an urbanization gradient. PLoS One, 9(8), e104679. https://doi.org/10.1371/journal.pone.010 4679

Fründ, J., Zieger, S. L., \& Tscharntke, T. (2013). Response diversity of wild bees to overwintering temperatures. Oecologia, 173(4), 1639-1648. https://doi.org/10.1007/s00442-013-2729-1

Gérard, M., Vanderplanck, M., Wood, T., \& Michez, D. (2020). Global warming and plant-pollinator mismatches. Emerging Topics in Life Sciences, https://doi.org/10.1042/ETLS20190139

Goldewijk, K. K., Beusen, A., van Drecht, G., \& de Vos, M. (2011). The HYDE 3.1 spatially explicit database of human-induced global land-use change over the past 12,000 years. Global Ecology and Biogeography, 20(1), 73-86. https://doi.org/10.1111/j.1466-8238.2010.00587.x

Goulson, D., Lye, G. C., \& Darvill, B. (2008). Decline and conservation of bumble bees. Annual Review of Entomology, 53(1), 191-208. https:// doi.org/10.1146/annurev.ento.53.103106.093454

Goulson, D., Nicholls, E., Botías, C., \& Rotheray, E. L. (2015). Bee declines driven by combined stress from parasites, pesticides, and lack of flowers. Science, 347(6229), 1255957. https://doi.org/10.1126/scien ce.1255957

Grab, H., Branstetter, M. G., Amon, N., Urban-Mead, K. R., Park, M. G., Gibbs, J., Blitzer, E. J., Poveda, K., Loeb, G., \& Danforth, B. N. (2019). Agriculturally dominated landscapes reduce bee phylogenetic diversity and pollination services. Science, 363(6424), 282-284. https:// doi.org/10.1126/science.aat6016

Greenleaf, S. S., Williams, N. M., Winfree, R., \& Kremen, C. (2007). Bee foraging ranges and their relationship to body size. Oecologia, 153(3), 589-596. https://doi.org/10.1007/s00442-007-0752-9

Hassall, C., Owen, J., \& Gilbert, F. (2017). Phenological shifts in hoverflies (Diptera: Syrphidae): Linking measurement and mechanism. Ecography, 40(7), 853-863. https://doi.org/10.1111/ecog.02623

He, F., \& Gaston, K. J. (2003). Occupancy, spatial variance, and the abundance of species. The American Naturalist, 162(3), 366-375. https:// doi.org/10.1086/377190

Hegland, S. J., Nielsen, A., Lázaro, A., Bjerknes, A.-L., \& Totland, Ø. (2009). How does climate warming affect plant-pollinator interactions? Ecology Letters, 12(2), 184-195. https://doi.org/10.1111/j.1461-0248.2008. 01269.x 
Isaac, N. J. B., Girardello, M., Brereton, T. M., \& Roy, D. B. (2011). Butterfly abundance in a warming climate: Patterns in space and time are not congruent. Journal of Insect Conservation, 15(1), 233-240. https://doi. org/10.1007/s10841-010-9340-0

Isaac, N. J. B., van Strien, A. J., August, T. A., de Zeeuw, M. P., \& Roy, D. B. (2014). Statistics for citizen science: Extracting signals of change from noisy ecological data. Methods in Ecology and Evolution, 5(10), 1052-1060. https://doi.org/10.1111/2041-210X.12254

Klein, A.-M., Vaissière, B. E., Cane, J. H., Steffan-Dewenter, I., Cunningham, S. A., Kremen, C., \& Tscharntke, T. (2007). Importance of pollinators in changing landscapes for world crops. Proceedings of the Royal Society of London B: Biological Sciences, 274(1608), 303-313. https://doi.org/10.1098/rspb.2006.3721

Kremen, C., Williams, N. M., \& Thorp, R. W. (2002). Crop pollination from native bees at risk from agricultural intensification. Proceedings of the National Academy of Sciences of the United States of America, 99(26), 16812-16816. https://doi.org/10.1073/pnas.262413599

Kuussaari, M., Bommarco, R., Heikkinen, R. K., Helm, A., Krauss, J., Lindborg, R., Öckinger, E., Pärtel, M., Pino, J., Rodà, F., Stefanescu, C., Teder, T., Zobel, M., \& Steffan-Dewenter, I. (2009). Extinction debt: A challenge for biodiversity conservation. Trends in Ecology \& Evolution, 24(10), 564-571. https://doi.org/10.1016/j.tree.2009.04.011

Larsen, T. H., Williams, N. M., \& Kremen, C. (2005). Extinction order and altered community structure rapidly disrupt ecosystem functioning. Ecology Letters, 8(5), 538-547. https://doi.org/10.1111/j.14610248.2005.00749.x

Le Féon, V., Schermann-Legionnet, A., Delettre, Y., Aviron, S., Billeter, R., Bugter, R., Hendrickx, F., \& Burel, F. (2010). Intensification of agriculture, landscape composition and wild bee communities: A large scale study in four European countries. Agriculture, Ecosystems \& Environment, 137(1), 143-150. https://doi.org/10.1016/j.agee.2010. 01.015

Luder, K., Knop, E., \& Menz, M. H. M. (2018). Contrasting responses in community structure and phenology of migratory and non-migratory pollinators to urbanization. Diversity and Distributions, 24(7), 919-927. https://doi.org/10.1111/ddi.12735

Maria, D., Magurran, A. E., Buckland, S. T., Anne, C., Chazdon, R. L., Colwell, R. K., Tom, C., Gaston, K. J., Gotelli, N. J., Kosnik, M. A., Brian, M. G., McCune, J. L., Hélène, M., Mumby, P. J., Lise, Ø., Angelika, S., \& Mark, V. (2013). Quantifying temporal change in biodiversity: Challenges and opportunities. Proceedings of the Royal Society B: Biological Sciences, 280(1750), 20121931. https://doi.org/10.1098/ rspb.2012.1931

Memmott, J., Craze, P. G., Waser, N. M., \& Price, M. V. (2007). Global warming and the disruption of plant-pollinator interactions. Ecology Letters, 10(8), 710-717. https://doi.org/10.1111/j.1461-0248.2007.01061.x

Nieto, A., Roberts, S. P. M., Kemp, J., Rasmont, P., Kuhlmann, M., García Criado, M., Biesmeijer, J. C., Bogusch, P., Dathe, H. H., De la Rúa, P., De Meulemeester, T., Dehon, M., Dewulf, A., Ortiz-Sánchez, F. J., Lhomme, P., Pauly, A., Potts, S. G., Praz, C., Quaranta, M., ... IUCN (International Union for Conservation of Nature). (2014). European red list of bees. Publications Office. Retrieved from http://bookshop. europa.eu/uri?target=EUB:NOTICE:KH0714078:EN:HTML

Ogilvie, J. E., Griffin, S. R., Gezon, Z. J., Inouye, B. D., Underwood, N., Inouye, D. W., \& Irwin, R. E. (2017). Interannual bumble bee abundance is driven by indirect climate effects on floral resource phenology. Ecology Letters, 20(12), 1507-1515. https://doi.org/10.1111/ ele.12854

Ollerton, J., Erenler, H., Edwards, M., \& Crockett, R. (2014). Extinctions of aculeate pollinators in Britain and the role of large-scale agricultural changes. Science, 346(6215), 1360-1362. https://doi.org/10.1126/ science. 1257259

Ollerton, J., Winfree, R., \& Tarrant, S. (2011). How many flowering plants are pollinated by animals? Oikos, 120(3), 321-326. https://doi. org/10.1111/j.1600-0706.2010.18644.x
Orme, D., Freckleton, R., Thomas, G., Petzoldt, T., Fritz, S., Isaac, N., \& Pearse, W. (2013). caper: Comparative Analyses of Phylogenetics and Evolution in R. Retrieved from https://CRAN.R-project.org/ package $=$ caper

Outhwaite, C. L., Chandler, R. E., Powney, G. D., Collen, B., Gregory, R. D., \& Isaac, N. J. B. (2018). Prior specification in Bayesian occupancy modelling improves analysis of species occurrence data. Ecological Indicators, 93, 333-343. https://doi.org/10.1016/j.ecolind.2018.05.010

Pagel, M. (1999). Inferring the historical patterns of biological evolution. Nature, 401(6756), 877-884. https://doi.org/10.1038/44766

Park, M. G., Blitzer, E. J., Gibbs, J., Losey, J. E., \& Danforth, B. N. (2015). Negative effects of pesticides on wild bee communities can be buffered by landscape context. Proceedings of the Royal Society B: Biological Sciences, 282(1809), 20150299. https://doi.org/10.1098/ rspb.2015.0299

Pickett, S. T. A. (1989). Space-for-time substitution as an alternative to long-term studies. In G. E. Likens (Ed.), Long-term studies in ecology: Approaches and alternatives (pp. 110-135). Springer. https://doi. org/10.1007/978-1-4615-7358-6_5

Pollard, E., \& Yates, T. J. (1994). Monitoring butterflies for ecology and conservation: The British butterfly monitoring scheme. Springer Science \& Business Media.

Potts, S. G., Biesmeijer, J. C., Kremen, C., Neumann, P., Schweiger, O., \& Kunin, W. E. (2010). Global pollinator declines: Trends, impacts and drivers. Trends in Ecology \& Evolution, 25(6), 345-353. https://doi. org/10.1016/j.tree.2010.01.007

Powney, G. D., Carvell, C., Edwards, M., Morris, R. K. A., Roy, H. E., Woodcock, B. A., \& Isaac, N. J. B. (2019). Widespread losses of pollinating insects in Britain. Nature Communications, 10(1), 1018. https:// doi.org/10.1038/s41467-019-08974-9

Rader, R., Bartomeus, I., Tylianakis, J. M., \& Laliberté, E. (2014). The winners and losers of land use intensification: Pollinator community disassembly is non-random and alters functional diversity. Diversity and Distributions, 20(8), 908-917. https://doi.org/10.1111/ddi.12221

Rafael Valdovinos-Núñez, G., Quezada-Euán, J. J. G., Ancona-Xiu, P., Moo-Valle, H., Carmona, A., \& Ruiz Sánchez, E. (2009). Comparative toxicity of pesticides to stingless bees (Hymenoptera: Apidae: Meliponini). Journal of Economic Entomology, 102(5), 1737-1742. https://doi.org/10.1603/029.102.0502

Rasmont, P., Franzen, M., Lecocq, T., Harpke, A., Roberts, S., Biesmeijer, K., Castro, L., Cederberg, B., Dvorak, L., Fitzpatrick, U., Gonseth, Y., Haubruge, E., Mahe, G., Manino, A., Michez, D., Neumayer, J., Odegaard, F., Paukkunen, J., Pawlikowski, T., ... Schweiger, O. (2015). Climatic risk and distribution atlas of European bumblebees. Biodiversity and Ecosystem Risk Assessment, 10, 1-236. https://doi. org/10.3897/biorisk.10.4749

Roy, D. B., \& Sparks, T. H. (2000). Phenology of British butterflies and climate change. Global Change Biology, 6(4), 407-416. https://doi. org/10.1046/j.1365-2486.2000.00322.x

Rudolf, V. H. W. (2019). The role of seasonal timing and phenological shifts for species coexistence. Ecology Letters, 22(8), 1324-1338. https://doi.org/10.1111/ele.13277

Scheper, J., Reemer, M., van Kats, R., Ozinga, W. A., van der Linden, G. T. J., Schaminée, J. H. J., Siepel, H., \& Kleijn, D. (2014). Museum specimens reveal loss of pollen host plants as key factor driving wild bee decline in The Netherlands. Proceedings of the National Academy of Sciences of the United States of America, 111(49), 17552-17557. https://doi.org/10.1073/pnas.1412973111

Sgrò, C. M., Terblanche, J. S., \& Hoffmann, A. A. (2016). What can plasticity contribute to insect responses to climate change? Annual Review of Entomology, 61(1), 433-451. https://doi.org/10.1146/annur ev-ento-010715-023859

Soroye, P., Newbold, T., \& Kerr, J. (2020). Climate change contributes to widespread declines among bumble bees across continents. Science, 367(6478), 685-688. https://doi.org/10.1126/science.aax8591 
Storkey, J., Meyer, S., Still, K. S., \& Leuschner, C. (2012). The impact of agricultural intensification and land-use change on the European arable flora. Proceedings of the Royal Society B: Biological Sciences, 279(1732), 1421-1429. https://doi.org/10.1098/rspb.2011.1686

Uhl, P., Franke, L. A., Rehberg, C., Wollmann, C., Stahlschmidt, P., Jeker, L., \& Brühl, C. A. (2016). Interspecific sensitivity of bees towards dimethoate and implications for environmental risk assessment. Scientific Reports, 6(1), 34439. https://doi.org/10.1038/srep34439

White, P., \& Kerr, J. T. (2006). Contrasting spatial and temporal global change impacts on butterfly species richness during the 20th century. Ecography, 29(6), 908-918. https://doi.org/10.1111/j.2006. 0906-7590.04685.x

Willi, Y., Van Buskirk, J., \& Hoffmann, A. A. (2006). Limits to the adaptive potential of small populations. Annual Review of Ecology, Evolution, and Systematics, 37(1), 433-458. https://doi.org/10.1146/annurev. ecolsys.37.091305.110145

Williams, N. M., Crone, E. E., Roulston, T. H., Minckley, R. L., Packer, L., \& Potts, S. G. (2010). Ecological and life-history traits predict bee species responses to environmental disturbances. Biological Conservation, 143(10), 2280-2291. https://doi.org/10.1016/j.biocon. 2010.03.024
Winfree, R., Aguilar, R., Vázquez, D. P., LeBuhn, G., \& Aizen, M. A. (2009). A meta-analysis of bees' responses to anthropogenic disturbance. Ecology, 90(8), 2068-2076. https://doi.org/10.1890/08-1245.1

Zhai, S., Song, G., Qin, Y., Ye, X., \& Lee, J. (2017). Modeling the impacts of climate change and technical progress on the wheat yield in inland China: An autoregressive distributed lag approach. PLoS One, 12(9), e0184474. https://doi.org/10.1371/journal.pone.0184474

\section{SUPPORTING INFORMATION}

Additional supporting information may be found online in the Supporting Information section.

How to cite this article: Duchenne F, Thébault E, Michez D, et al. Long-term effects of global change on occupancy and flight period of wild bees in Belgium. Glob Change Biol. 2020;00:1-14. https://doi.org/10.1111/gcb.15379 